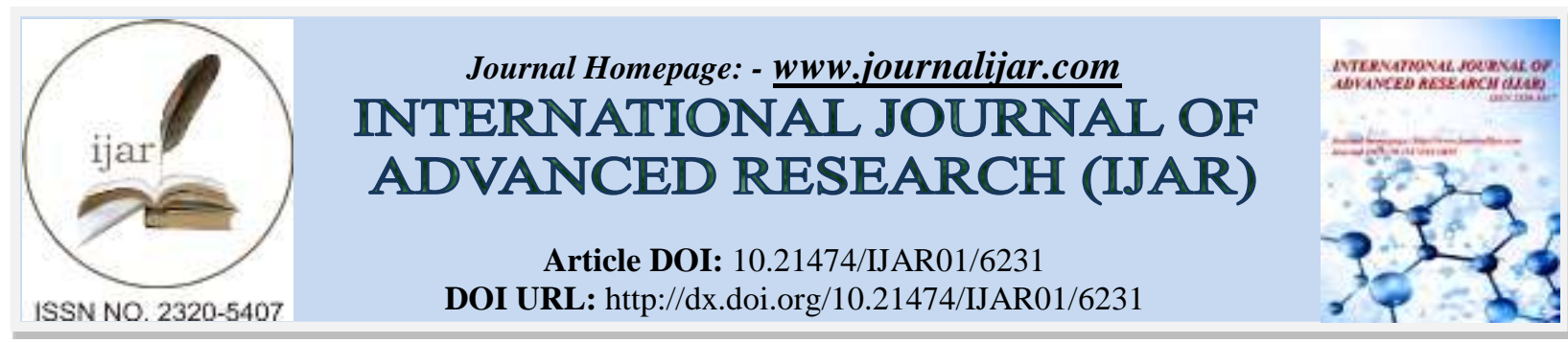

RESEARCH ARTICLE

\title{
EFFECT OF DIFFERENT MALE-FEMALE BROODSTOCK RATIO ON THE INDUCED BREEDING PERFORMANCE OF Clarias gariepinus.
}

${ }^{*}$ Maradun. H. F. ${ }^{1}$, Ahmad. M. ${ }^{1}$, Sahabi. A. M. ${ }^{1}$,Umar. F. ${ }^{2}$, Ibrahim. J. $Z^{3}$ and Adamu. $I^{4}$.

1. Department of Fisheries and Aquaculture, Usmanu Danfodiyo University, PMB 2346, Sokoto, Nigeria.

2. Department of Water Resources, Aquaculture and Fisheries Technology, Federal University of Technology, Minna.

3. Aquaculture and Biotechnology Programme, National Institute for Freshwater Fisheries Research, New Bussa.

4. Department of Biological Sciences, Kebbi State University of Science and Technology, Aliero.

\section{Manuscript Info}

Manuscript History

Received: 05 November 2017

Final Accepted: 07 December 2017

Published: January 2018

\section{Abstract}

Induced breeding of African catfish Clarias gariepinus was conducted to investigate the effect of different male-female broodstock ratio on the breeding performance. The broodstock for the experiment were collected from the National Institute for Freshwater Fisheries Research, New Bussa and the experiment was carried out at the hatchery section of Happy Island Garden, Sokoto. The experiment was set up in a completely randomized design (CRD) with treatment combinations as; 1:1 male:female broodstock ratio (Treatment A), 1:2 male:female broodstock ratio (Treatment B) and 1:3 male:female broodstock ratio (Treatment C). The broodstocks were injected with ovulin hormone at the recommended dosage of $0.5 \mathrm{ml} / \mathrm{kg}$ body weight for the females and half dosage was administered to the males. The result showed that Treatment $\mathrm{A}$ had the highest fertilization rate $(71.66 \%)$ and hatching rate $(88.70 \%)$ as well as survival rate $(73.17 \%)$ followed by Treatment B with $68.69 \%$ fertilization but had the least values for hatching rate $(80.58 \%)$ and survival rate $(70.83 \%)$. Treatment $\mathrm{C}$ had the lowest value for fertilization (64.25\%) but was following Treatment $\mathrm{A}$ in terms of hatching rate $(84.54 \%)$ and survival rate $(72.13 \%)$. However, no significant differences $(p>0.05)$ exist between the treatments in terms of the breeding performance parameters examined. The present study showed that $C$. gariepinus of mean body weight of $600 \mathrm{~g}$ can successfully be induced with ovulin hormone at different broodstock ratios to ovulate and obtain eggs and larvae of good quality.

Copy Right, IJAR, 2018,. All rights reserved.

\section{Introduction:-}

The African catfish is widely considered as the leading cultured fish in Nigeria and it is considered as the most sought after fish species among fish farmers and consumers because it commands a very good commercial value (Oladosu et al., 1993). It is a very important fish in the commercial fisheries in Nigeria because of its desirable qualities such as ability to tolerate low dissolved oxygen, ability to produce in captivity and fast growth rate. It is also observed to have efficient feed conversion capacity (Nweke and Ugwumba, 2005).

Corresponding Author:- Maradun, H. F.

Address:- Department of Fisheries and Aquaculture, Usmanu Danfodiyo University, PMB 2346,

Sokoto. Nigeria. 
According to Odedeyi and Eniade (2014) the fish farming industry in Nigeria appears to be more focused towards the quality and quantity of eggs rather than that of sperm, even though the sperm quantity and quality of male broodstock impacts greatly on the production of healthy and abundant larvae. It has been shown that in most commercial hatcheries where African catfish seeds are being propagated, semen is often inadequate both in terms of quantity and quality and does not always give successful fertilization in the artificial breeding (Rurangwa et al., 2004). When male broodstock is limited, it is especially important to ensure that the sperm quality is good enough to achieve high percentage fertilization.

A major pre-requisite for successful fish farming enterprise is a reliable and consistent source of fish seeds (fingerlings) of the commercially important species (Nwuba and Aguigwo, 2002). The surest and most reliable source of supply is to produce the fingerlings under a controlled system, usually in a hatchery as was emphasized by Ezechi and Nwuba (2007). The objective of this study was to determine the most appropriate male to female of catfish (Clarias gariepinus) broodstock for induced breeding.

\section{Methodology:-}

\section{A. Study area}

The experiment was carried out at the hatchery section of Happy Island Garden, Sokoto. The broodstock for the experiment were collected from the National Institute for Freshwater Fisheries Research, New Bussa. The fish was conditioned at the hatchery complex of the farm and was fed commercially produced industrial feed (Coppens) at $3 \%$ body weight twice daily for two weeks. Water quality parameters such as Temperature, $\mathrm{pH}$ and dissolved oxygen were monitored during the period of the experiment. The Water temperature was determined using mercuryin-glass thermometer, $\mathrm{pH}$ and Dissolved Oxygen (DO) were measured using $\mathrm{pH}$ and oxygen meter respectively (APHA, 1995).

\section{B. Experimental design and setup}

A total of 15 broodstocks (6 males and 9 females) were used for the experiment. The experiment was setup in a Completely Randomized Design (CRD) where the broodstocks were allotted into three treatments and each treatment replicated three times. The treatments were; Treatment A (1:1 male-female broodstock ratio), Treatment B (1:2 male-female broodstock ratio) and Treatment $\mathrm{C}$ (1:3 male-female broodstock ratio).

\section{Hormone injection}

Artificial hormone (Ovulin) was used as the hormone for inducing ovulation at the recommended dosage of $0.5 \mathrm{ml} / \mathrm{kg}$ body weight of female broodstock and half dosage was administered to male broodstock (Potongkam and Miller, 2006). The experimental fish were weighed to determine the appropriate hormonal dose. Fish were injected intramuscularly above the lateral line towards the dorsal section and pointed towards the ventral side (Nwokoye et al., 2007).

\section{Procurement of ripe eggs and milt}

Checking of ovulation started $6 \mathrm{~h}$ after injecting the fish with hormone and continued at one-hour intervals (Brzuska, 2004). Females were tested for ovulation by hand stripping of the abdomen (Richter et al., 1987). It was gently squeezed towards the genital opening. Broodfish was considered ovulated upon yielding an ample amount of green brown eggs.

The eggs were collected from each ovulated female through stripping by gently pressing the abdomen of the fish. The eggs were collected into clean bowls labelled according to the treatments. The weights of the eggs collected were recorded. Milt was obtained by sacrificing the males. Each male was dissected carefully and their milt sac obtained. A small incision was made on the lobes of the testes with a sharp razor blade and the milt was squeezed into a dry Petri dish containing the collected eggs (Nwadukwe et al., 1993)

\section{E. Artificial fertilization}

Dry method of fertilization was used where the milt obtained from the male fishes was squeezed gently onto the stripped eggs obtained from the females accordingly and stirred gently and thoroughly using plastic spoon for about 1-2 minutes to allow contact and adequate fertilization (Megbowon et al., 2013), after which normal saline was added before spreading the eggs on the spawning nets in the incubation units prepared earlier for that purpose (Delince et al., 1987; Viveen et al., 1985). 


\section{F. Incubation and hatching}

Two grams of the fertilized eggs were collected and distributed in a single layer on the spawning nets in the well aerated incubation bowls provided for the experiment for easy assessment of fertilization and hatchability rates (Brzuska, 2004; Gadissa and Devi, 2013; Okoro et al., 2007). The viable and dead eggs were determined and counted. The viable eggs were translucent while the non-viable eggs were white and opaque and these were carefully removed by siphoning. Hatching started at about 20 hours after incubation and lasted for about 6 hours. Percentage hatchability was estimated 24 hours after hatching was completed. One hundred of the hatchlings were weighed, their weights multiplied by total weight of larvae in each of the bowl to estimate total hatchability per bowl. Three days after yolk sac was absorbed, larval survival was also estimated.

Care of the larvae started immediately after hatching. Siphoning was carried out on a daily basis in all the bowls to prevent fouling and infection and subsequent mortality of the hatched larvae. Water quality parameters such as the temperature and $\mathrm{pH}$ were continuously monitored.

\section{G. Data collection}

Data on spawning fecundity, percent fertilization, percent hatchability and larval survival were collected

Fecundity was estimated according to Haylor and Oyegunwa (1993) as;

Total weight of eggs $\mathrm{x}$ no. of eggs per gram

Fertilization rate was estimated according to Adebayo and Popoola (2008) as follows;

$$
\text { Fertilization rate }(\%) \text { : } \frac{\text { Number of fertilized eggs }}{\text { Total number of eggs collected }} \times 100
$$

Hatchability rate was calculated according to Adebayo and Popoola (2008) as follows;

$$
\text { Hatchability rate }(\%) \text { : } \frac{\text { Number of hatched eggs }}{\text { Total number of eggs fertilized }} \times 100
$$

Larval survival was calculated thus;

$$
\text { Larval survival rate }(\%) \text { : } \frac{\text { Total number of larvae - Number of dead larvae }}{\text { Total number of larvae }} \times 100
$$

\section{H. Data analysis}

Data obtained on the induced breeding performance (fertilization, hatchability and larval survival) were analyzed using one-way analysis of variance (ANOVA) and treatment means were separated using Duncan multiple range test where significant differences exist $(\mathrm{P}<0.05)$ by using SPSS package version 20.

\section{Results:-}

The weight of the broodstocks used for the experiment was $600 \mathrm{~g}$ for all the treatments. Treatment A (1:1 male: female broodstock ratio) produced the highest weight of eggs $(86.67 \mathrm{~g})$ and the highest fecundity $(54,922)$, followed by treatment B (1:2 male to female broodstock ratio) that produced egg weight of $86.33 \mathrm{~g}$ but with the lowest fecundity of 53,532 among the treatments. Treatment $\mathrm{C}$ with a ratio of 1:3 male to female broodstock produced the lowest weight of eggs $(85.33 \mathrm{~g})$ but has a slightly higher fecundity $(53,676)$ than treatment B $(53,532)$. However, no significant differences $(\mathrm{p}>0.05)$ exist between the treatments.

The average latency period to complete ovulation recorded during the experiment was 11 hours for all the treatments at an average temperature of $26^{\circ} \mathrm{C}$.

Table 1:- Initial mean weight, dosage, mean egg weight, fecundity and latency period of $C$. gariepinus at different broodstock ratio

\begin{tabular}{|l|l|l|l|}
\hline \multirow{2}{*}{ Parameters } & Treatments & B \\
\cline { 2 - 4 } & A & $1: 2$ & $1: 3$ \\
\hline Broodstock ratio (M:F) & $1: 1$ & 600.00 & 600.00 \\
\hline Initial weight (g) & 600.00 & 0.30 & 0.30 \\
\hline Dosage(ml) & 0.30 & 86.33 & 85.33 \\
\hline Egg weight (g) & 86.67 & 53,532 & 53,676 \\
\hline Fecundity & 54,922 & 11.00 & 11.00 \\
\hline Latency period (h) & 11.00 & 20.5 & 20.00 \\
\hline Incubation period (h) & 20.00 & \\
\hline
\end{tabular}

$\mathrm{A}=1$ male to 1 female, $\mathrm{B}=1$ male to 2 females, $\mathrm{C}=1$ male to 3 females 
The result of the induced breeding of $C$. gariepinus at different broodstock ratio showed that treatment A with a ratio of 1 male to 1 female had the highest percentage fertilization rate $(71.66 \%)$ followed by treatment $\mathrm{B}$ with broodstock ratio of 1 male to 2 females which had percentage fertilization of $68.69 \%$ while Treatment $\mathrm{C}$ with broodstock ratio of 1 male to 3 females had the lowest percentage fertilization among the treatments with $64.25 \%$. however, there was no significant difference $(\mathrm{p}>0.05)$ between the treatment means.

Hatchability rate was highest in treatment A $(88.70 \%)$ followed by treatment $\mathrm{C}(84.54 \%)$ while treatment $\mathrm{C}$ had the lowest percentage hatchability among the treatments with $80.58 \%$. however, there was no significant differences $(\mathrm{p}<0.05)$ among the treatment means.

Larval survival rate was highest (73.17\%) in treatment A with 1 male to 1 female broodstock ratio and lowest in treatment B (70.83\%) that has broodstock ratio of 1 male to 2 females. Treatment $\mathrm{C}$ with 1 male to 3 female broodstock ratio had survival rate of $72.13 \%$, but no significant differences exist among the treatment means.

Table 2:- Fertilization rate, hatchability and larval survival rate of $C$. gariepinus at different broodstock ratio

\begin{tabular}{|l|l|l|l|}
\hline \multirow{2}{*}{ Parameter } & Treatments & B & C \\
\cline { 2 - 4 } & A & $68.69 \pm 1.15$ & $64.25 \pm 14.03$ \\
\hline Fertilization rate (\%) & $71.66 \pm 6.28$ & $80.58 \pm 7.51$ & $84.54 \pm 5.17$ \\
\hline Hatchability rate (\%) & $88.70 \pm 7.84$ & $70.83 \pm 6.88$ & $72.13 \pm 8.39$ \\
\hline Larval survival (\%) & $73.17 \pm 3.35$ & C & \\
\hline
\end{tabular}

$\mathrm{A}=1$ male to 1 female ratio, $\mathrm{B}=1$ male to 2 females ratio, $\mathrm{C}=1$ male to 3 females ratio

The mean temperature of the water recorded in the experimental units during the trial was $26^{0} \mathrm{C}$ while the mean $\mathrm{pH}$ value was 7.05 and the dissolved oxygen concentration was $6.20 \mathrm{mg}$.

\section{Discussion and conclusion:-}

The size of the broodstocks used in this study was $600 \mathrm{~g}$ for all the treatments and this was in agreement with the findings of Viveen et al. (1985) who reported that C. gariepinus becomes mature as from $200 \mathrm{~g}$ body weight.

The temperature ranges of $26.50^{\circ} \mathrm{C}$ to $27.20^{\circ} \mathrm{C}$ recorded during the experiment was higher than $22^{\circ} \mathrm{C}$ that was observed by Viveen et al. (1985) for C. gariepinus that exhibited latency period in excess of 15 hours. While Zonneveld and Surasana (1988) obtained their best results at $25^{\circ} \mathrm{C}$. The mean $\mathrm{pH}$ value of 7.05 and dissolved oxygen concentration of 6.20 were within normal range for culture fishes (Viveen et al., 1985). According to Woynarovich and Horvath (1980), a number of environmental factors such as temperature, pH, dissolved oxygen and calmness play decisive role in ovulation and that temperature is of vital importance.

The incubation period of $20 \mathrm{~h}$ at a temperature of $27^{\circ} \mathrm{C}$ was similar to what was obtained by Viveen et al., (1985) for C. gariepinus but was in disagreement with $16-22 \mathrm{~h}$ at the $30^{\circ} \mathrm{C}$ reported by Ajana and Anyanwu (1995) on $C$. gariepinus. According to Legendre (1986), the time taken to complete any stage may be dependent on water temperature and often decreases with an increase in temperature.

The mean percentage fertilization recorded in the experiment may be an indication of the efficacy of ovulin in induced breeding of $C$. gariepinus regardless of the ratio of broodstock used and can result in high fertilization of eggs of $C$. gariepinus as Adebayo and Popoola (2008) reported fertilization rate of $84.50 \%$ for $C$. gariepinus while Haniffa and Sridhar (2002) reported fertilization of $70 \%$ for spotted murrel (Channa punctatus) by administration of Ovaprim in both cases. The high larval production $(88.70 \%, 80.58 \%$ and $84.54 \%)$ in the three treatments out of which $73.17 \%, 70.83 \%$ and $72.13 \%$ survived respectively, indicates an overall good egg quality and effectiveness of the hormone used in the experiment in inducing ovulation and spawning in the African catfish. However, there was no significant difference $(\mathrm{p}>0.05)$ in the percentage egg fertilization, percentage hatchability and survival in all the treatments.

In conclusion, it has been shown from the result of this experiment that the response of $C$. gariepinus to Ovulin at different broodstock ratios was found to be good considering the breeding success in this study in terms of fecundity, fertilization, hatchability and larval survival. Therefore, the present study showed that C. gariepinus of 
mean body weight of $600 \mathrm{~g}$ can successfully be induced with ovulin hormone at different broodstock ratios to ovulate and obtain eggs and larvae of good quality.

\section{References:-}

1. Adebayo, O. T. and Popoola, O. M. (2008). Comparative evaluation of efficacy and cost of synthetic and nonsynthetic hormones for artificial breeding of African catfish (Clarias gariepinus, Burchell 1822). Journal of Fisheries and Aquatic Science, 3, 66-71.

2. Ajana, A. M. and Anyanwu, P. E. (1995). Hetero-clarias fingerlings production. Aquaculture Development Programme Extension Guide No. 7. The National Agriculture Research Project (NARP).

3. APHA. (1995). Standard methods for the examination of water and wastewater. Washington DC, USA: American Public Health Association.

4. Brzuska, E. (2004). Artificial spawning of carp (Cyprinus carpio L.); differences between the effects of reproduction in females of Hungarian, Polish and French origin treated with carp pituitary homogenate or [DTle6, ProNHEt9] GnRH (Lecirelin). Aquacult Res., 35(14), 1318-1327.

5. Delince, G. A., Campbell, D., Janssen, J. A. and Kutty, M. N. (1987). Seed Production. Port Harcourt, Nigeria: Africa Regional Aquaculture Centre.

6. Ezechi, C. U. and Nwuba, L. A. (2007). Effect of different dietary items on the growth of African catfish hybrid Heterobranchus bidorsalis X Clarias gariepinus. Animal Research International, 4(2), $662-665$.

7. Gadissa, S. and Devi, S. P. (2013). Evaluation of spawning induction of African catfish (Clarias gariepinus) by heteroplastic hypophysation. International Journal of Aquatic Sciences, 1(1), 22-25.

8. Haniffa, M. A. and Sridhar, S. (2002). Induced spawning of spotted Murrel (Channa punctatus) and Catfish (Hetreopneustes fossilis) using human Chorlonic gonadotropin and synthetic hormone (Ovaprim). Vet. Arhir., 71, 51-56.

9. Haylor, G. S. and Oyegunwa, O. (1993). The onset of air breathing and the development of accessory breathing organs in the Africa catfish Clarias gariepinus (Burchell) in relation to temperature. Aquaculture and Fishery Management, 24, 253-260.

10. Legendre, M. (1986). Seasonal changes in sexual maturity and fecundity and HCG-induced breeding of the catfish, Heterobranchus bidorsalis Val. (Clariidae) reared in Ebrie Lagoon (Ivory coast). Aquaculture, 55, 201213.

11. Megbowon, I., Fashina-Bombata, H. A., Akinwale, M. M.-A., Hammed, A. M., Okunade, O. A. and Mojekwu, T. O. (2013). Breeding performance of Clarias gariepinus obtained from Nigerian waters. IOSR Journal of Agriculture and Veterinary Science, 6(3), 6-9.

12. Nwadukwe, F. O., Ayinla, O. A. and Abby-Kalio, N. J. (1993). Effect of various doses of Acetone-dried powdered carp pituitatry extract and season on hatchery propagation of Heterobranchus longifilis. J. Aqua. Trop., 8, 33-40.

13. Nweke, S. I. and Ugwumba, A. A. (2005). Effect of replacement of fishmeal with duckweed (Lemna paucicostata) meal on the growth of Clarias gariepinus (Burchell, 1822) fingerlings. Proceedings of the 20th Annual Conference of Fisheries Society of Nigeria (pp. 163-167). Port Harcourt, 14th - 18th November, 2005: FISON.

14. Nwokoye, C. O., Nwuba, L. A. and Eyo, J. E. (2007). Induced propagation of African clariid catfish, Heterobranchus bidorsalis (Geoffrey Saint Hillarie, 1809) using synthetic and homoplastic hormones. Afr. J. Biotechnol., 6(23), 2687-2693.

15. Nwuba, L. A. and Aguigwo, J. N. (2002). Studies on the effects of different food items on the survival of Hatchlings of Clarias anguillaris. Journal of Aquatic Science, 17(2), 121-124.

16. Odedeyi, D. O. and Eniade, A. A. (2014). Semen qaulity and spermatozoa morphology of Clarias gariepinus broodstock fed two different feed levels. Researcher, 6(1), 28-32.

17. Okoro, C. B., Nwadukwe, F. O. and Ibemere, I. (2007). The use of ovaprim in oocyte maturation and ovulation in Clarias gariepinus (Burchell, 1822). African Journal of Applied Zoology and Environmental Biology, 9, 8384.

18. Oladosu, G. A., Ayinla, O. A., Adeyemo, A. A., Yakubu, A. F. and Ajani, A. A. (1993). Comparative study of reproductive capacity of the African Catfish species Heterobranchus bidorsalis, Clarias gariepinus and their Hybrid. Port Harcourt: African Regional Aquaculture Centre Tech. paper 92.

19. Potongkam, K. and Miller, J. (2006). Manual on catfish hatchery and production. A guide for small to medium sclae hatchery and farm producers in Nigeria. Aquaculture and Inland Fisheries Project. 
20. Richter, C. J., Eding, E. H., Goos, H. T., De Leeuw, R., Scott, A. P. and Van Oordt, P. G. (1987). The effect of pimozide/LHRHa and 17a-hydroxyprogesterone on plasma steroid levels and ovulation in the African catfish, Clarias gariepinus. Aquaculture, 63(1), 157-168.

21. Rurangwa, E., Kime, D. E., Ollevier, F. and Nash, J. P. (2004). The measurement of sperm motility and factors affecting sperm quality in cultured fish. Aquaculture, 23(4), 1-28.

22. Viveen, W. J., Richter, C. J., Van Ordt, P. G., Jansen, J. A. and Huisman, E. A. (1985). Practical manual for the culture of the African Catfish Clarias gariepinus. The Hague, Netherlands: Section for Research and Development Cooperation.

23. Woynarovich, E. and Horvath, L. (1980). Artificial propagation of warm water fin-fishes: A manual for extension. FAO Fish Tech. Paper 201.

24. Zonneveld, I. S. and Surasana, E. (1988). Ecosystem invento-ryhegetation survey (Komering basin, Sumatra). ITC Journal, 1, 67-75. 